\author{
Dominika \\ Wilczyńska (DD \\ $1 \cdot \mathrm{A}, \mathrm{B}, \mathrm{C}, \mathrm{D}, \mathrm{E}, \mathrm{F}$ \\ Fianye $\mathrm{Li}$ (D) \\ $1 \cdot \mathrm{B}, \mathrm{D}, \mathrm{E}, \mathrm{F}$ \\ Yin Yang (D) \\ $2 \cdot \mathrm{B}, \mathrm{D}$ \\ Hongying Fan $\mathbb{D}$ \\ $2 \cdot B, D$
}

\title{
Fear of COVID-19 changes the motivation for physical activity participation: Polish-Chinese comparisons
}

\section{BACKGROUND}

COVID-19 has brought people many negative emotions, such as fear and anxiety about the epidemic. However when people in different countries face the COVID-19 epidemic, the impact is also different due to different cultural and sports habits. Therefore, this study compares China and Poland's sports motivations in the face of COVID-19 anxiety to find out the cultural differences behind them.

PARTICIPANTS AND PROCEDURE

In the study were $N=674$ participants (female $n=407$, male $n=260$, other $n=4$ ). Their average age was $M=29.86$, $S D=11.03$. There were $n=381$ participants in the Chinese sample, and $n=293$ in Polish. The scales used for the purpose of the study were the Inventory of Physical Activity Objectives (IPAO) and the Coronavirus Anxiety Scale (CAS).
RESULTS

The study results showed that the increased level of COVID-19 anxiety changed selected motives for physical activity, and different changes of motives characterized women and men as well as people of different ages. As predicted in the study model, culture was the moderator of the shifts of the selected motives.

\section{CONCLUSIONS}

The understanding of what motivates individuals to participate in sport seems to have significant value, especially for health practitioners and researchers to design appropriate interventions and programs to increase activity.

\section{KEY WORDS}

COVID-19 anxiety; motives for physical activity; nationality

ORgANIZATION - 1: Gdansk University of Physical Education and Sport, Gdansk, Poland · 2: Beijing Sport University,

Beijing, China · 3: Zhengzhou University, Zhengzhou, China

AUthors' CONTRiButions - A: Study design - B: Data collection - C: Statistical analysis - D: Data interpretation .

E: Manuscript preparation · F: Literature search · G: Funds collection

Corresponding author - Prof. Mariusz Lipowski, Department of Psychology, Gdansk University of Physical Education and Sport, 1 Kazimierza Górskiego Str., 80-336 Gdansk, Poland, e-mail: mariusz.lipowski@awf.gda.pl

to Cite this ARTICLE - Wilczyńska, D., Li, J., Yang, Y., Fan, H., Liu, T., \& Lipowski, M. (2021). Fear of COVID-19 changes

the motivation for physical activity participation: Polish-Chinese comparisons. Health Psychology Report, 9(2), 138-148.

https://doi.org/10.5114/hpr.2021.105007

RECEIVED 12.02.2021 · REVIEWED 18.03.2021 · ACCEPTED 20.03.2021 · PUBLISHED 06.04.2021 


\section{BACKGROUND}

The novel coronavirus (COVID-19) was first detected in Wuhan, China, in December 2019 among patients who suffered from an unidentified form of viral pneumonia with the same history of visiting the Huanan sea-food market (Zhu et al., 2020). Its pervasive transmission was recognized by the World Health Organization (WHO) as a pandemic. Uncertain or even faked information about factors related to virus transmission as well as the number of infected, and the actual mortality rate, has led to doubt and fear in the world's population (Peeri et al., 2020). These uncertainties have created a host of new challenges that have brought profound changes and have affected the population's lifestyles and mental health (Ornell et al., 2020). Moreover, nowadays the situation raises a number of questions, including whether there is a fear/stress pandemic concomitant with the COVID-19 pandemic, how this fear influences people's motives for different activities and what the remedy for this situation is. It is important to underline that fear causes anxiety and increases the stress levels among healthy individuals. Furthermore, the restrictions made by the governments for different activities have adversely affected the health-related quality of life of humans compared to pre-pandemic times. Among all the obstacles people have faced in the time of COVID-19, the restriction on outdoor physical activities has seemed to be very difficult to manage. At the same time, participation in some activities, especially indoor ones, could cause the fear of COVID-19. As the studies show, the emotions and states of fear and anxiety have a significant impact on the level of people's physical activity (Topcu et al., 2020). Therefore the main aim of this study is to measure this impact but on the motives for physical activity.

The motives for practicing physical activity and sport have been among the main priorities of researchers and other specialists to understand the reasons that lead individuals to exercise. The objectives determine such essential aspects as strength, direction, and resistance that the individual brings to activity and achievement. The character and complexity of the motives usually determine the level of engagement, and significantly contribute to the desire to either continue the activity or to quit (Lipowski \& Ussorowska, 2018). Motivation factors for physical activity are relatively diverse, and adequate quality of sports motivation can promote people's physical and mental health. However, five motives are usually most cited for engagement in sport among the adult population: health and fitness; improvement of physical appearance; enjoyment; socialization; psychological benefits physical activity brings (Angosto et al., 2020). Moreover, people's motives for physical activity participation differ for example according to gender, age, living area, type of activity as well as education level. Louw et al. (2012) underline that the significant and main motives for women undertaking physical activity are weight control and appearance, while among male respondents strength and endurance as well as feeling good are ranked highest. In the study of Leyton Román et al. (2018), men got higher scores in autonomy and intention of doing physical activities, and women got high scores in social interaction through sport. Moreover, individuals from rural areas obtained higher scores than those from urban areas in self-directed motivation. Hickey and Mason (2017) found that compared to women, men participate in more hours of exercise and more types of activities and have a greater number of motivators, while women reported having more barriers to exercise than men and lower levels of sport participation and have fewer motivators. The same authors also underline that an individual's age is an important factor that influences the types of physical activities pursued. Endurance exercises, such as running, tend to be more popular with younger adults, while walking is one of the most popular forms of exercise among older adults as well as swimming and floor exercises. Women, regardless of age, show a preference for leisure physical activities such as cycling, yoga. walking, dancing, and treadmill.

The lockdown is a significant barrier that prevents participation in exercise, and people have the tendency to switch from physical activity to different ones. A study on Chinese adults proved that a twoto-three-month lockdown had mixed effects. The participants were found to have focused more on their eating quality and other patterns, which had a positive influence on their quality of life (Wang et al., 2020). However, experts strongly recommend continuing exercising during the prolonged quarantine to avoid health problems, such as increasing obesity, depression, infections, and cardiovascular diseases, as much as possible. When studying the impact of COVID-19 on the level and patterns of exercise in the adult population, Constandt et al. (2020) observed a general increase in exercise frequency and also in sedentary behavior. Moreover, people above the age of 55, who previously were low active, reported exercising more during the lockdown. On the other hand, people in the same age group, who were already highly active before COVID-19 and also with low education, who additionally used to exercise with friends or in a sports club, and those who were not using online tools to exercise, reported exercising less during the lockdown. The main reasons for a self-reported exercise reduction were: having less time, sitting more, and missing the familiar way and competitive element of exercising. Also, cross-cultural studies show different approaches toward exercises among respondents from different cultures and nationalities. A study on selected European countries proved that the Netherlands is characterized by a sig-
Impact of COVID-19 anxiety on $P A$ motives cross-cultural differences 
nificantly higher level of physical activity than Poland, the Czech Republic, and Germany. The authors also emphasize that identification of the motives and reasons for differences in physical activity levels might help exclude the barriers and increase participation in physical activity in different countries and worldwide (Maciaszek et al., 2020).

The study of whether the fear of COVID-19 changes the motivation for physical activity participation has particular research value. It seems essential to estimate motives for participation in physical activity, which could help promote motives that increase sports participation. Moreover, as China and Poland have had different cultures, histories, and sports concepts since ancient times, through comparative research, we can understand the different motives for physical activity and psychological states and changes of the residents of the two countries during the COVID-19 epidemic. Once motivators for physical activity during such tough times as the pandemic are identified, programs can be designed to maximize motivation factors and minimize barriers to activity such as fear of the virus and how to follow the COVID-19 pandemic and to adopt the "new normal" of the future. Moreover, this study may bring useful and timely information to develop new action plans for health care providers and the management staff of gyms and other community fitness centers to ensure services in the event of another outbreak. The study tries to answer the research question whether the fear of COVID-19 changes the motives for physical activity and whether the culture is the moderator of those changes.

\section{PARTICIPANTS AND PROCEDURE}

\section{PARTICIPANTS}

In the study were $N=674$ participants (female $n=407$, male $n=260$, other $n=4$ ). Their average age was $M=29.86, S D=11.03$. There were $n=381$ participants in the Chinese sample, and $n=293$ in the Polish one. The analysis showed that Chinese participants were younger than Polish ones, $M=26.58, S D=9.27$ vs. $M=34.11, S D=11.68, t=9.32, p<.001$, and more male participants were in the Chinese sample than in the Polish one $(n=172$ vs. $n=235) \chi^{2}(4)=93.34$, $p<.001$.

\section{RESEARCH TOOLS}

The Inventory of Physical Activity Objectives (IPAO; Lipowski \& Zaleski, 2015) is used to assess the motivational function of an objective of physical activity. The IPAO consists of questions about the variety of forms, volume, frequency of PA, as well as sociodemographic variables. Participants are also asked about:

- engagement in competitive sports (both currently and in the past),

- attitude towards passive engagement in sports (e.g. as a fan).

The above 12 objectives are estimated on a Likerttype scale (1-5).

The subsequent part of the questionnaire concerns the motivational function of the PA objectives: motivational value, time management, persistence in action and motivational conflict. As well as these dimensions, the test also measures the multidimensionality of objectives. Raw scores are transformed into sten values (Lipowski \& Ussorowska, 2018). The inventory has been shown to have acceptable psychometric properties. Cronbach's reliability coefficient was .78 (Lipowski \& Zaleski, 2015). In the current study $\alpha$ for the Polish and Chinese (respectively) was .80 and .86 .

The Coronavirus Anxiety Scale (CAS) is a tool developed by Lee (2020). The scale consists of 5 questions about emotional states during the COVID-19 pandemic. The CAS is a mental health screener created to efficiently and effectively support healthcare professionals and researchers in identifying probable cases of dysfunctional anxiety associated with the COVID-19 crisis. The respondents describe on a Likert-type scale (1 - not at all, 2 - rarely, less than a day or two, 3 - several days, 4 - more than 7 days, 5 - nearly every day over the last 2 weeks) how often during the last two weeks they have experienced distinct physiologically based fear and anxiety reactions to coronavirus related thoughts and information. The scale has been shown to be valid and reliable with $\alpha=.93$ (Lee, 2020). In the current study, the Cronbach's $\alpha$ for Polish and Chinese respectively was .80 and .91 .

\section{MOTIVATING GOALS AT T1 (BEFORE COVID-19) AND T2 (DURING COVID-19)}

In order to reduce multicollinearity, in the statistical model, between the motivating goals measured at $\mathrm{t} 1$ (before COVID-19) and at t2 (during COVID-19), we computed the new 12 variables using the following formula: Changes in a motivating goal $=$ a motivating goal at $\mathrm{t} 2$ - a motivating goal at $\mathrm{t} 1$. A higher score indicates an increased level of the motivating goal during COVID-19 in comparison to the previous period.

\section{RESEARCH MODEL}

Our conceptualization was formulated as follows. We predict that COVID-19 anxiety, gender and age 
will be related to the increased level of the motivating goals. However, we predict that culture (Chinese vs. Polish) will moderate the predicted relations. The research model is presented in Figure 1.

\section{MODELING METHOD}

To assess predictive power of the research model structural equation modeling was conducted in WarpPLS 7.0 software (Kock, 2010, 2020). In congruence with Dijkstra and Hensler (2015) the Consistent PLS algorithm was selected to establish path estimates in the proposed model. The fit statistics shown in Table 1 indicate that the tested model had small collinearity within the path model (AVIF) and measurement model (AFVIF) (Kock, 2015; Kock \& Mayfield, 2015) and low/moderate predictive power (GoF) (Tenenhaus et al., 2005). The path signs (SPR) and path values (SSR) in the model were similar to the signs and values of the independent zero-order correlations between the tested variables (Pearl, 2009; Tenenhaus et al., 2005). The analysis also displayed a very good data fit to the measurement model of latent variables (SRMR, SMAR, $\chi^{2}$ ).

\section{PROCEDURE}

The procedure carried out in this study consisted of an online questionnaire survey. The questionnaires were distributed among Polish and Chinese populations. The period in which the survey was ongoing was between April and June, 2020, in the period of the world pandemic situation. The data used for this study was part of a larger survey, and the questionnaires that formed this study took around 10 minutes to complete. The protocol of this study was approved by the Ethics Board for Research Projects at the Institute of Psychology, University of Gdansk, Poland (decision no. 33/2020), and registered in Protocol Registration and Results System - ClinicalTrials.gov https://clinicaltrials.gov/ct2/show/NCT04432038.

\section{RESULTS}

To assess interaction effects, the ANOVA was conducted. The two-factor model was formulated as follows: 2 (gender: male vs. female) vs. 2 (country: Poland vs. China). Dependent variables included particular motivating goals and COVID-19 anxiety. The analysis showed that both factors had an influence on the company of other people and escape from everyday life. Analysis of the simple interaction effect showed that in the Chinese group, females had a higher score on the company of other people measure than males, $M=-0.51, S D=1.12$

\section{Figure 1}

\section{Research mode of culture}

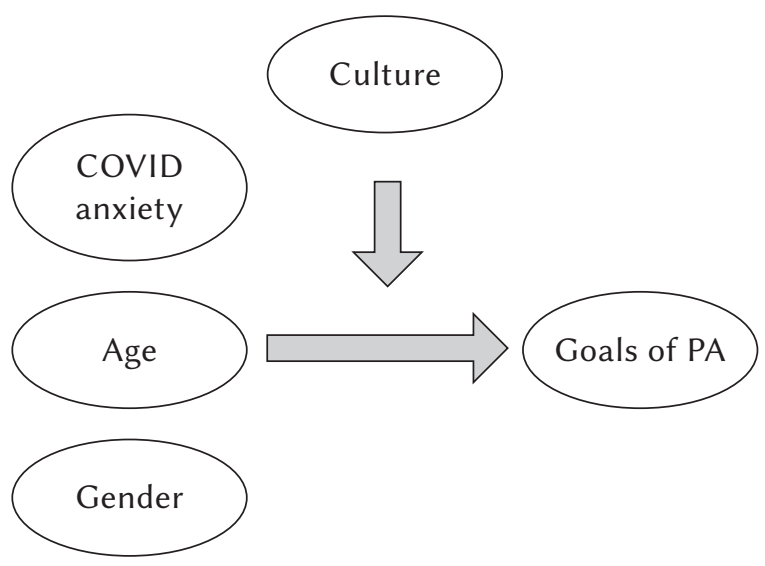

Impact of COVID-19 anxiety on $P A$ motives cross-cultural differences

\section{Table 1}

Model fit and quality indices in tested model

\begin{tabular}{lc}
\hline Coefficient & Value \\
\hline Tenenhaus GoF (GoF) & 0.14 \\
Simpson's paradox ratio (SPR) & 0.97 \\
Statistical suppression ratio (SSR) & 1.00 \\
SRMR & 0.04 \\
AVIF & 1.01 \\
AFVIF & 1.29 \\
SMAR & 0.02 \\
\hline
\end{tabular}

Note. AVIF - average variance inflation factor (accepted if AVIF $\leq 5.00$, ideally AVIF $\leq 3.30$ ); AFVIF - average full variance inflation factor (accepted if AVIF $\leq 5.00$, ideally AVIF $\leq 3.30$ ); GoF goodness of fit (low if $\mathrm{GoF} \geq 0.10$, moderate if $\mathrm{GoF} \geq 0.25$, high if GoF $\geq 0.36$ ); SPR - Simpson's paradox ratio (accepted if SPR $\geq 0.70$, ideally $S P R=1.00) ; S S R-$ statistical suppression ratio (accepted if SSR $\geq 0.70$, ideally SSR $=1.00$ ); SRMR - standardized root mean squared residual (accepted if $S R M R \leq 0.10$ ); SMAR - standardized mean absolute residual (accepted if SMAR $\leq 0.10)$

vs. $M=-0.94, S D=1.31, F(1,610)=12.65, p<.001$, $\eta^{2}=.02$. However, in the Polish group this difference was insignificant $F(1,610)=0.41, p>.05, \eta^{2}=.00$. Further analysis showed that both factors had influenced escape from everyday life. Analysis of the simple interaction effect showed that in the Polish group, females had a higher score on escape from everyday life than males, $M=0.48, S D=0.98$ vs. $M=0.06$, $S D=0.77, F(1,610)=10.08, p<.01, \eta^{2}=.02$. However, in the Chinese group this difference was insignificant $F(1,610)=0.00, p>.05, \eta^{2}=.00$. There were no other significant interaction effects. Table 2 shows the ANOVA's interaction estimates. Figures 2 and 3 show patterns of described results. 
Table 2

ANOVA's estimates of interaction effects 2 (gender: male vs. female) vs. 2 (country: Poland vs. China)

\begin{tabular}{lccc}
\hline Factor: Gender ${ }^{*}$ Country & $F$ & $p$ & $\eta^{2}$ \\
\hline Health & 0.90 & .344 & .00 \\
Physical fitness, being in shape & 1.16 & .283 & .00 \\
Company of other people & $\mathbf{6 . 5 2}$ &. $\mathbf{0 1 1}$ & .01 \\
Fit, shapely body & 1.13 & .289 & .00 \\
Well-being & 0.21 & .645 & .00 \\
Being physically active according to fashion & 0.48 & .488 & .00 \\
Boosting confidence, gaining appreciation from others & 0.04 & .841 & .00 \\
Pleasure from physical activity & 0.03 & .871 & .00 \\
Escape from everyday life & $\mathbf{6 . 7 9}$ & .009 & .01 \\
Managing stress & 2.39 & .123 & .00 \\
Fulfilling the need for activity & 2.87 & .091 & .00 \\
Promoting PA by setting a behavioral example & 0.18 & .674 & .00 \\
COVID-19 anxiety & 1.46 & .228 & .00 \\
\hline
\end{tabular}

Figure 2

ANOVA's estimates of interaction effects 2 (gender: male vs. female) vs. 2 (country: Poland vs. China) on company of other people

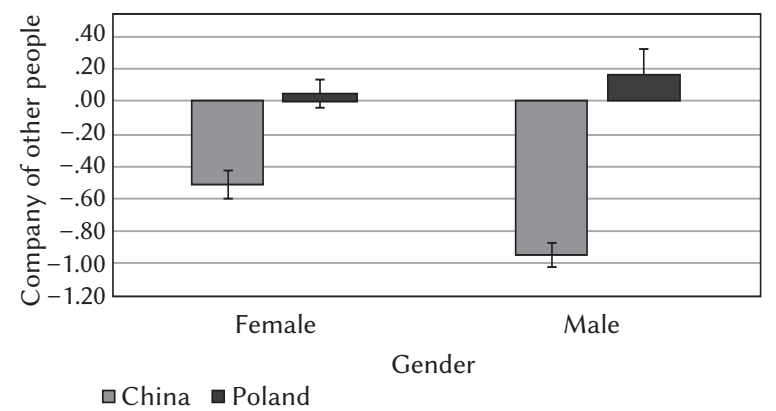

Analysis of the results, calculated in both groups, showed that an increased level of COVID-19 anxiety was related to an increased level of the fit, shapely body, escape from everyday activity, managing stress, and promoting PA by setting a behavioral example. The analysis also showed the male participants had a higher level of physical fitness, being in shape, and well-being, but female participants had a higher level of the company of other people, being physically active according to fashion, boosting confidence, escape from everyday life, and managing stress. Further analysis showed that older age was related to a higher level of the company of other people, and to a lower level of physical fitness, being in shape, and well-being. Results are shown in Table 3.
Figure 3

ANOVA's estimates of interaction effects 2 (gender: male vs. female) vs. 2 (country: Poland vs. China) on escape from everyday life

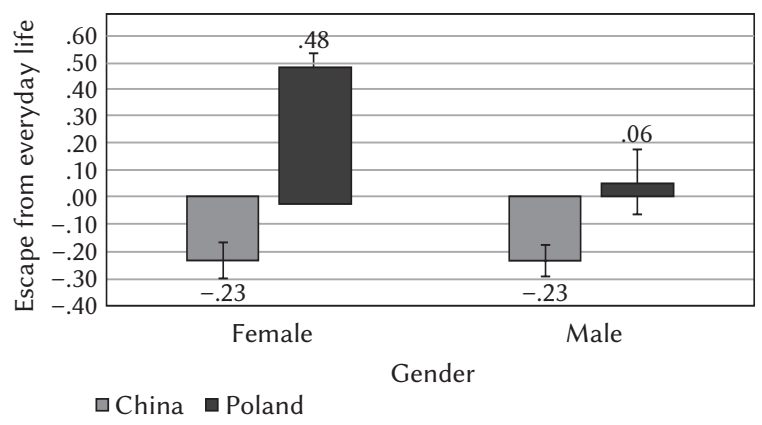

\section{MODERATION ANALYSIS}

To compare direct relations between two different groups (Chinese vs. Polish sample), a multi-group analysis (MGA) was conducted in WarpPLS 7.0 software (Kock, 2014; Rodríguez-Entrena et al., 2018). The MGA aims to verify differences between groups in terms of estimated path values. MGA analysis showed that in the Polish sample the increased level of COVID-19 anxiety was related to the increased level of escape from everyday life measure, but in the Chinese sample that relation was significantly smaller (it was close to zero). Further analysis showed that in the Chinese sample the female participants had a higher level of the company of other people than 
in the Polish sample, but in the Polish sample the female participants had a higher level of escape from everyday life than in the Chinese sample. The results also showed that in the Polish sample, the male participants had a higher level of fulfilling the need for activity than the male participants in the Chinese sample. Further analysis also showed that older age was related to an increased level of the company of other people measure in the Chinese sample, but in the Polish sample that relation was inverted. The last significant differences in MGA analysis showed that increasing age was related to lowered levels of escape from everyday life and managing stress in the Polish sample, but these relationships were close to zero in the Chinese sample. Results are shown in Table 4 .

Table 3

Path estimates in the empirical SEM-PLS model

\begin{tabular}{|c|c|c|c|c|c|}
\hline \multirow[t]{2}{*}{ Path } & \multirow[t]{2}{*}{$\beta$} & \multirow[t]{2}{*}{$t$} & \multirow[t]{2}{*}{$p$} & \multicolumn{2}{|c|}{$95 \% \mathrm{Cl}$} \\
\hline & & & & Lower & Upper \\
\hline COVID-19 anxiety $\rightarrow$ Health & .03 & 0.70 & .243 & -.05 & .10 \\
\hline COVID-19 anxiety $\rightarrow$ Physical fitness, being in shape & .00 & -0.10 & .459 & -.08 & .07 \\
\hline COVID-19 anxiety $\rightarrow$ Company of other people & .03 & 0.67 & .253 & -.05 & .10 \\
\hline COVID-19 anxiety $\rightarrow$ Fit, shapely body & .07 & 1.92 & .027 & .00 & .15 \\
\hline COVID-19 anxiety $\rightarrow$ Well-being & -.01 & -0.24 & .405 & -.09 & .07 \\
\hline $\begin{array}{l}\text { COVID-19 anxiety } \rightarrow \text { Being physically active according } \\
\text { to fashion }\end{array}$ & .01 & 0.23 & .408 & -.07 & .08 \\
\hline $\begin{array}{l}\text { COVID-19 anxiety } \rightarrow \text { Boosting confidence, gaining } \\
\text { appreciation from others }\end{array}$ & .06 & 1.64 & .051 & -.01 & .14 \\
\hline COVID-19 anxiety $\rightarrow$ Pleasure from physical activity & .05 & 1.29 & .098 & -.03 & .13 \\
\hline COVID-19 anxiety $\rightarrow$ Escape from everyday life & .08 & 2.15 & .016 & .01 & .16 \\
\hline COVID-19 anxiety $\rightarrow$ Managing stress & .11 & 2.82 & .002 & .03 & .18 \\
\hline COVID-19 anxiety $\rightarrow$ Fulfilling the need for activity & .00 & 0.12 & .454 & -.07 & .08 \\
\hline $\begin{array}{l}\text { COVID-19 anxiety } \rightarrow \text { Promoting PA by setting } \\
\text { a behavioral example }\end{array}$ & .08 & 2.06 & .020 & .00 & .15 \\
\hline Gender $\rightarrow$ Health & .02 & 0.50 & .309 & -.06 & .09 \\
\hline Gender $\rightarrow$ Physical fitness, being in shape & .15 & 4.08 & $<.001$ & .08 & .23 \\
\hline Gender $\rightarrow$ Company of other people & -.19 & -5.02 & $<.001$ & -.26 & -.12 \\
\hline Gender $\rightarrow$ Fit, shapely body & .04 & 1.14 & .127 & -.03 & .12 \\
\hline Gender $\rightarrow$ Well-being & .09 & 2.31 & .011 & .01 & .16 \\
\hline $\begin{array}{l}\text { Gender } \rightarrow \text { Being physically active according } \\
\text { to fashion }\end{array}$ & -.10 & -2.61 & .005 & -.17 & -.03 \\
\hline $\begin{array}{l}\text { Gender } \rightarrow \text { Boosting confidence, gaining } \\
\text { appreciation from others }\end{array}$ & -.06 & -1.69 & .046 & -.14 & .01 \\
\hline Gender $\rightarrow$ Pleasure from physical activity & -.01 & -0.29 & .386 & -.09 & .06 \\
\hline Gender $\rightarrow$ Escape from everyday life & -.18 & -4.83 & $<.001$ & -.26 & -.11 \\
\hline Gender $\rightarrow$ Managing stress & -.12 & -3.04 & .001 & -.19 & -.04 \\
\hline Gender $\rightarrow$ Fulfilling the need for activity & .05 & 1.35 & .090 & -.02 & .13 \\
\hline Gender $\rightarrow$ Promoting PA by setting a behavioral example & -.04 & -1.11 & .135 & -.12 & .03 \\
\hline
\end{tabular}

Impact of COVID-19 anxiety on $P A$ motives cross-cultural differences 
Table 3

Table 3 continued

\begin{tabular}{lrrrrr}
\hline Path & $\beta$ & $t$ & $p$ & \multicolumn{2}{c}{$95 \% \mathrm{Cl}$} \\
\cline { 4 - 6 } & & & & Lower & Upper \\
\hline Age $\rightarrow$ Health & .02 & 0.46 & .322 & -.06 & .09 \\
Age $\rightarrow$ Physical fitness, being in shape & -.12 & -3.13 & $<.001$ & -.19 & -.05 \\
Age $\rightarrow$ Company of other people & .12 & 3.06 & .001 & .04 & .19 \\
Age $\rightarrow$ Fit, shapely body & -.05 & -1.19 & .118 & -.12 & .03 \\
Age $\rightarrow$ Well-being & -.10 & $-\mathbf{2 . 6 6}$ & .004 & -.18 & -.03 \\
Age $\rightarrow$ Being physically active according to fashion & .05 & 1.41 & .079 & -.02 & .13 \\
Age $\rightarrow$ Boosting confidence, gaining appreciation & .06 & 1.63 & .052 & -.01 & .14 \\
from others & & & & & .02 \\
Age $\rightarrow$ Pleasure from physical activity & & -.05 & -1.37 & .086 & -.13 \\
Age $\rightarrow$ Escape from everyday life & .02 & 0.42 & .337 & -.06 & .09 \\
Age $\rightarrow$ Managing stress & .00 & -0.05 & .480 & -.08 & .07 \\
Age $\rightarrow$ Fulfilling the need for activity & -.04 & -0.90 & .183 & -.11 & .04 \\
Age $\rightarrow$ Promoting PA by setting a behavioral example & .02 & 0.55 & .292 & -.05 & .10 \\
\hline
\end{tabular}

Note. Measurements related to the motivating goals were computed using the following formula: Changes in a motivating goal = a motivating goal at $\mathrm{t} 2$ - a motivating goal at $\mathrm{t} 1$. Higher score indicates an increased motivating goal during COVID-19 in comparison to the previous period.

Table 4

Results of the conducted PLS-SEM multigroup analysis

\begin{tabular}{|c|c|c|c|c|}
\hline Path & China & Poland & $t$ & $p$ \\
\hline COVID-19 anxiety $\rightarrow$ Health & .03 & .02 & 0.15 & .442 \\
\hline COVID-19 anxiety $\rightarrow$ Physical fitness, being in shape & -.03 & -.09 & 0.89 & .187 \\
\hline COVID-19 anxiety $\rightarrow$ Company of other people & .03 & .11 & 1.08 & .140 \\
\hline COVID-19 anxiety $\rightarrow$ Fit, shapely body & .09 & .00 & 1.11 & .134 \\
\hline COVID-19 anxiety $\rightarrow$ Well-being & -.01 & -.05 & 0.47 & .319 \\
\hline COVID-19 anxiety $\rightarrow$ Being physically active according to fashion & .05 & -.05 & 1.24 & .107 \\
\hline $\begin{array}{l}\text { COVID-19 anxiety } \rightarrow \text { Boosting confidence, gaining appreciation } \\
\text { from others }\end{array}$ & .10 & .05 & 0.63 & .264 \\
\hline COVID-19 anxiety $\rightarrow$ Pleasure from physical activity & .05 & .05 & 0.08 & .470 \\
\hline COVID-19 anxiety $\rightarrow$ Escape from everyday life & .03 & .21 & 2.25 & .012 \\
\hline COVID-19 anxiety $\rightarrow$ Managing stress & .08 & .18 & 1.31 & .095 \\
\hline COVID-19 anxiety $\rightarrow$ Fulfilling the need for activity & -.01 & -.02 & 0.15 & .439 \\
\hline $\begin{array}{l}\text { COVID-19 anxiety } \rightarrow \text { Promoting PA by setting a behavioral } \\
\text { example }\end{array}$ & .10 & .03 & 0.92 & .179 \\
\hline Gender $\rightarrow$ Health & -.03 & .06 & 1.12 & .132 \\
\hline Gender $\rightarrow$ Physical fitness, being in shape & .06 & -.02 & 1.05 & .148 \\
\hline Gender $\rightarrow$ Company of other people & -.16 & .05 & 2.67 & .004 \\
\hline
\end{tabular}


Table 4

Table 4 continued

\begin{tabular}{|c|c|c|c|c|}
\hline Path & China & Poland & $t$ & $p$ \\
\hline Gender $\rightarrow$ Fit, shapely body & -.02 & .07 & 1.18 & .119 \\
\hline Gender $\rightarrow$ Well-being & .00 & -.04 & 0.49 & .313 \\
\hline Gender $\rightarrow$ Being physically active according to fashion & -.09 & -.01 & 1.04 & .150 \\
\hline Gender $\rightarrow$ Boosting confidence, gaining appreciation from others & -.03 & -.02 & 0.15 & .440 \\
\hline Gender $\rightarrow$ Pleasure from physical activity & -.06 & -.02 & 0.53 & .297 \\
\hline Gender $\rightarrow$ Escape from everyday life & -.01 & -.16 & 1.93 & .027 \\
\hline Gender $\rightarrow$ Managing stress & .01 & -.11 & 1.51 & .066 \\
\hline Gender $\rightarrow$ Fulfilling the need for activity & -.02 & .12 & 1.81 & .035 \\
\hline Gender $\rightarrow$ Promoting PA by setting a behavioral example & -.03 & .01 & 0.52 & .303 \\
\hline Age $\rightarrow$ Health & .08 & -.03 & 1.32 & .093 \\
\hline Age $\rightarrow$ Physical fitness, being in shape & -.03 & .01 & 0.51 & .307 \\
\hline Age $\rightarrow$ Company of other people & .13 & -.11 & 3.17 & $<.001$ \\
\hline Age $\rightarrow$ Fit, shapely body & -.04 & .01 & 0.57 & .285 \\
\hline Age $\rightarrow$ Well-being & .00 & -.04 & 0.57 & .285 \\
\hline Age $\rightarrow$ Being physically active according to fashion & .05 & .00 & 0.76 & .225 \\
\hline Age $\rightarrow$ Boosting confidence, gaining appreciation from others & .03 & .02 & 0.18 & .427 \\
\hline Age $\rightarrow$ Pleasure from physical activity & .01 & -.06 & 0.85 & .197 \\
\hline Age $\rightarrow$ Escape from everyday life & .06 & -.22 & 3.57 & $<.001$ \\
\hline Age $\rightarrow$ Managing stress & .00 & -.15 & 1.96 & .025 \\
\hline Age $\rightarrow$ Fulfilling the need for activity & -.04 & .01 & 0.55 & .291 \\
\hline Age $\rightarrow$ Promoting PA by setting a behavioral example & .02 & -.03 & 0.67 & .251 \\
\hline
\end{tabular}

Note. Measurements related to the motivating goals were computed using the following formula: Changes in a motivating goal = a motivating goal at $\mathrm{t} 2-$ a motivating goal at $\mathrm{t} 1$. Higher score indicates an increased motivating goal during COVID-19 in comparison to the previous period.

\section{DISCUSSION}

The current study aimed to investigate, firstly, whether coronavirus anxiety, gender, and age are related to an increased level of particular physical activity motives, and secondly, whether the aspect of culture (Chinese vs. Polish) moderates the predicted relations. As the results showed, the changes in respondents' selected physical activity motives were related to fear of COVID-19. The participants from Poland and China practiced physical activity to manage the stressful situation and escape from everyday routines and trained to be in good shape and set a behavioral example. Similarly, in a study on motives for practicing sport among 1025 amateurs, Angosto et al. (2020) found that the main motives during confinement were psychological motives related to improvement or management of general or emotional well-being.
Also, research on younger adults presented results in line with the current study, in which one of the main objectives apart from psychological ones was being fit, a mainly physical motive. The present study results also correspond with the outcomes showing that people tend to engage in sport or physical activity to disconnect from daily family or work routine and be in a fit state. On the other hand, research on young adults practicing different fitness activities indicated health and skill development motives (Angosto et al., 2020). Kaur et al. (2020) underlined that regular fitness workouts at home during the lockdown significantly helped participants to overcome psychological issues and fitness concerns. Generally, the motives of enjoyment and stress relief are also significant predictors of engagement in sport and physical activity among exercisers and amateur athletes (Moradi et al., 2020). Moreover, Violant-Holz
Impact of COVID-19 anxiety on $P A$ motives cross-cultural differences 
et al. (2020) in a systematic review underlined that physical activity could be an effective strategy to face the COVID-19 pandemic psychological effects and decrease the prevalence of psychiatric disorders. Also, findings of Ugbolue et al. (2020) highlighted the health consequences of individual distress caused by COVID-19.

The current study's analysis also demonstrated that the male participants were characterized by a higher level of such goals as physical fitness, shape, and well-being. In comparison, female participants had a higher level of other people's company, being physically active according to fashion, boosting confidence, escape from everyday life, and managing stress during the COVID-19 pandemic than before it. Moreover, Chinese females had a significantly higher level of the company of other people motive than Chinese males. On the other hand, Polish females were characterized by a substantially higher escape from everyday life than Polish males. The body of studies shows that there have been gender differences in physical activity objectives. Some studies indicated that females were more motivated by appearance and physical condition than males, whereas males were more oriented toward competition and mastery. Also, Lipowski and Ussorowska (2018) proved that women have been engaging in physical activity to achieve physical fitness, health, and well-being, while among male respondents, the most crucial motive was improving physical ability and fitness. Stereotypical gender requirements could explain those differences still existing in the society where females need to be bodily beautiful while males need to be bodily strong. Studies on Spanish respondents also revealed interesting findings that females who were not active before the pandemic significantly increased their physical activity practice during the pandemic, presenting better adaptation to the circumstances and digital changes than males (García-Tascón et al., 2020). Moreover, the results of this study also revealed a significant relation between selected motives and age. The older respondents were characterized by a higher level of the company of other people's motive and a lower level of physical fitness, being in shape, and wellbeing objectives. Studies on people aged between 30 and 55 years found that the most important motives for them for practicing sports were mood management, skill development, medical requirements, and enjoyment (Jancey et al., 2009). Some studies indicated that adults practice sports to maintain health, middle-aged adults to cope with stress as well as due to psychological conditions and other's expectations, and older adults to manage chronic health conditions (Molanorouzi et al., 2015; Morris \& Roychowdhury, 2020).

The second step of the study was to assess the impact of the culture as a moderator of the relation between coronavirus anxiety, age and gender, and increased level of different physical activity motives. The results confirmed the prediction that culture is a moderator of those relations. COVID anxiety significantly increased the motive of escape from everyday life in the Polish group compared to Chinese respondents. Some studies also indicate a significant negative correlation between the development of the pandemic and people's sports activities. For example, research on respondents from the United States underlines that physical activity decreased by an average of $32 \%$, and among those who self-isolated, the maximum reduction was $43 \%$ (Meyer et al., 2020). The influence of gender on the motivation of sports activities in Polish and Chinese samples varies and shows significant differences in three aspects: the company of other people, escape from everyday life, fulfilling the need for activity. Chinese female respondents were more often motivated by other people when practicing sport, whereas Polish females were significantly more motivated by escaping from everyday life during the pandemic. In contrast, Polish male participants' motivation to be physically active was fulfilling the need for activity compared to Chinese males. Furthermore, this gender effect could be explained by Poland's more individualistic characteristic as a European country and the more collective characteristic of China. Research across most countries demonstrates that women are less active than men and the global average for inactive women is $31.7 \%$ vs. $23.4 \%$ inactive men (Health, 2019).

The authors also considered the effect of culture as a moderator of the relation between age and level of sport motives. There were significant differences between China and Poland in three aspects: the company of other people, escape from everyday life, and managing stress. The results show that in China, age is positively correlated with doing physical activity for the company of other people, while in Poland this relation is inverted. We could assume that the older Polish people become, the more individualistically they are doing sports, compared to the Chinese, who participate in physical activity for social contact. Interestingly, young adults from the Polish sample significantly more often were physically active to deal with stress during the pandemic. On the other hand, this relation was close to zero among Chinese participants. From a broader perspective, those results underline the national and cultural differences in coping with social distancing and isolation in current world conditions. Some researchers confirm that physical activity could be one of the possible coping strategies for today's challenges (Violant-Holz et al., 2020). Furthermore, understanding what motivates individuals to participate in sport and the factors that impact motives for that participation seems to be very important, especially for health practitioners and researchers to design appropriate interventions 
and programs to increase activity (Morris \& Roychowdhury, 2020).

There are a few limitations of the study. First of all, the time of the pandemic for the two countries is different. China has been considerably longer in the COVID-19 pandemic situation than Poland, and people's emotions and overall mental conditions may differ. Secondly, other independent variables such as religion, marital status, residence, education level, and earnings could be considered in future studies.

\section{CONCLUSIONS}

The study's findings confirmed the presented model and the pandemic context's influence, which forced the world population to follow social distancing policies and regulations and maintain compulsory confinement conditions at home. The COVID anxiety among respondents influenced the level of selected motives, and this significant change was also moderated by the respondent's culture as well as gender and age. However, future studies should consider the phase of the pandemic in which a particular country exists. Other socio-demographic aspects such as place of residence, income, and ethnicity should be analyzed. The aspect of the character of physical activity itself seems to be worth considering as well as the training loads.

\section{ACKNOWLEDGMENTS}

We would like to share our great appreciation for all the respondents who participated in the online survey for their contributions to this research. We would like to mention as well that all the authors have no conflicts of interest.

\section{RefERENCES}

Angosto, S., Berengüí, R., Vegara-Ferri, J. M., \& LópezGullón, J. M. (2020). Motives and commitment to sport in amateurs during confinement: a segmentation study. International Journal of Environmental Research and Public Health, 17, 7398. https:// doi.org/10.3390/ijerph17207398

Constandt, B., Thibaut, E., De Bosscher, V., Scheerder, J., Ricour, M., \& Willem, A. (2020). Exercising in times of lockdown: an analysis of the impact of COVID-19 on levels and patterns of exercise among adults in Belgium. International Journal of Environmental Research and Public Health, 17, 4144. https://doi.org/10.3390/ijerph17114144

Dijkstra, T. K., \& Henseler, J. (2015). Consistent partial least squares path modeling. Management Information Systems Quarterly, 39, 297-316. https:// doi.org/10.25300/MISQ/2015/39.2.02
García-Tascón, M., Sahelices-Pinto, C., MendañaCuervo, C., \& Magaz-González, A. M. (2020). The impact of the COVID-19 confinement on the habits of PA practice according to gender (male/ female): Spanish case. International Journal of Environmental Research and Public Health, 17, 6961. https://doi.org/10.3390/ijerph17196961

Health, T. L. P. (2019). Time to tackle the physical activity gender gap. The Lancet Public Health, 4, e360. https://doi.org/10.1016/S2468-2667(19)30135-5

Hickey, M. E., \& Mason, S. E. (2017). Age and gender differences in participation rates, motivators for, and barriers to exercise. Modern Psychological Studies, 22, 10-19.

Jancey, J. M., Clarke, A., Howat, P., Maycock, B., \& Lee, A. H. (2009). Perceptions of physical activity by older adults: a qualitative study. Health Education Journal, 68, 196-206. https://doi.org/ 10.1177/0017896909339531

Kaur, H., Singh, T., Arya, Y. K., \& Mittal, S. (2020). Physical fitness and exercise during the COVID-19 pandemic: a qualitative enquiry. Frontiers in Psychology, 11, 590172. https://doi.org/10.3389/fpsyg. 2020.590172

Kock, N. (2010). Using WarpPLS in e-collaboration studies: an overview of five main analysis steps. International Journal of E-Collaboration, 6, 1-11. https://doi.org/10.4018/jec.2010100101

Kock, N. (2014). Advanced mediating effects tests, multi-group analyses, and measurement model assessments in PLS-based SEM. International Journal of E-Collaboration, 10, 1-13. https://doi.org/ 10.4018/ijec.2014010101

Kock, N. (2015). Common method bias in PLS-SEM: a full collinearity assessment approach. International Journal of E-Collaboration, 11, 1-10. https:// doi.org/10.4018/ijec.2015100101

Kock, N. (2020). WarpPLS User Manual: Version 7.0 (7th ed.). ScriptWarp Systems.

Kock, N., \& Mayfield, M. (2015). PLS-based SEM algorithms: The good neighbor assumption, collinearity, and nonlinearity. Information Management and Business Review, 7, 113-130. https://doi. org/10.22610/imbr.v7i2.1146

Lee, S. L. (2020). Coronavirus Anxiety Scale: a brief mental health screener for COVID-19 related anxiety. Death Studies, 44, 393-401. https://doi.org/10. 1080/07481187.2020.1748481

Leyton Román, M., García Matador, J., Fuentes García, J. P., \& Jiménez Castuera, R. (2018). Análisis de variables motivacionales y de estilos de vida saludables en practicantes de ejercicio físico en centros deportivos en función del género [Analysis of motivational variables and healthy lifestyles in sports center practitioners by gender]. Retos: Nuevas Perspectivas de Educación Física, Deporte y Recreación, 34, 166-171. https://doi.org/10.47197/ retos.v0i34.58281
Impact of COVID-19 anxiety on $P A$ motives cross-cultural differences 
Lipowski, M., \& Ussorowska, A. (2018). The motivational function of an objective in physical activity and sport. Current Issues in Personality Psychology, 6, 57-66. https://doi.org/10.5114/CIPP.2018.72054

Lipowski, M., \& Zaleski, Z. (2015). Inventory of Physical Activity Objectives - a new method of measuring motives for physical activity and sport. Health Psychology Report, 1, 47-58. https://doi. org/10.5114/hpr.2015.49462

Louw, A. J., Van Biljon, A., \& Mugandani, S. C. (2012). Exercise motivation and barriers among men and women of different age groups. African Journal for Physical, Health Education, Recreation \& Dance, 18, 759-768.

Maciaszek, J., Ołpińska-Lischka, M., Pospieszna, B., Knisel, E., Honsová, Š., Epping, R., \& Bronikowski, M. (2020). Physical activity rates of male and female students from selected European physical education universities. Trends in Sport Sciences, 27, 63-69. https://doi.org/10.23829/TSS.2020.27.2-3

Meyer, J., McDowell, C., Lansing, J., Brower, C., Smith, L., Tully, M., \& Herring, M. (2020). Changes in physical activity and sedentary behavior in response to COVID-19 and their associations with mental health in 3052 US adults. International Journal of Environmental Research and Public Health, 17, 6469. https://doi.org/10.3390/ijerph17186469

Molanorouzi, K., Khoo, S., \& Morris, T. (2015). Motives for adult participation in physical activity: Type of activity, age, and gender. BMC Public Health, 15, 66. https://doi.org/10.1186/s12889-015-1429-7

Moradi, J., Bahrami, A., \& Dana, A. (2020). Motivation for participation in sports based on athletes in team and individual sports. Physical Culture and Sport. Studies and Research, 85, 14-21 https:// doi.org/10.2478/pcssr-2020-0002

Morris, T., \& Roychowdhury, D. (2020). Physical activity for health and well-being: The role of motives for participation. Health Psychology Report, 8, 391-407. https://doi.org/10.5114/hpr.2020.100111

Ornell, F., Schuch, J. B., Sordi, A. O., \& Kessler, F. H. P. (2020). "Pandemic fear" and COVID-19: Mental health burden and strategies. Brazilian Journal of Psychiatry, 42, 232-235. https://doi.org/10.1590/ 1516-4446-2020-0008

Pearl, J. (2009). Causality: Models reasoning, and interference (2nd ed.). Cambridge University Press.

Peeri, N. C., Shrestha, N., Rahman, M. S., Zaki, R., Tan, Z., Bibi, S., Baghbanzadeh, M., Aghamohammadi, N., Zhang, W., \& Haque, U. (2020). The SARS, MERS and novel coronavirus (COVID-19) epidemics, the newest and biggest global health threats: What lessons have we learned? International Journal of Epidemiology, 49, 717-726. https:// doi.org/10.1093/ije/dyaa033

Rodríguez-Entrena, M., Schuberth, F., \& Gelhard, C. (2018). Assessing statistical differences between parameters estimates in Partial Least Squares path modeling. Quality \& Quantity, 52, 57-69. https://doi.org/10.1007/s11135-016-0400-8

Tenenhaus, M., Vinzi, V. E., Chatelin, Y. M., \& Lauro, C. (2005). PLS path modeling. Computational Statistics \& Data Analysis, 48, 159-205. https://doi. org/10.1016/j.csda.2004.03.005

Topcu, Z. G., Kaygısız, B. B., \& Demiralp, C. (2020). How are the physical activity and anxiety levels of the university students affected during the coronavirus (COVID-19) pandemic? Baltic Journal of Health and Physical Activity, 1, 33-40. https://doi. org/10.29359/BJHPA.2020.Suppl.1.03

Ugbolue, U., Duclos, M., Urzeala, C., Berthon, M., Kulik, K., Bota, A., Thivel, D., Bagheri, R., Gu, Y., Baker, J., Andant, N., Pereira, B., Rouffiac, K., Clinchamps, M., Dutheil, F., \& on behalf of the COVISTRESS Network (2020). An assessment of the novel COVISTRESS Questionnaire: COVID-19 impact on physical activity, sedentary action and psychological emotion. Journal of Clinical Medicine, 9, 3352. https://doi.org/10.3390/jcm9103352

Violant-Holz, V., Gallego-Jiménez, M. G., GonzálezGonzález, C. S., Muñoz-Violant, S., Rodríguez, M. J., Sansano-Nadal, O., \& Guerra-Balic, M. (2020). Psychological health and physical activity levels during the COVID-19 pandemic: a systematic review. International Journal of Environmental Research and Public Health, 17, 9419. https://doi.org/10.3390/ ijerph17249419

Wang, X., Lei, S. M., Le, S., Yang, Y., Zhang, B., Yao, W., Gao, Z., \& Cheng, S. (2020). Bidirectional influence of the COVID-19 pandemic lockdowns on health behaviors and quality of life among Chinese adults. International Journal of Environmental Research and Public Health, 17, 5575. https://doi. org/10.3390/ijerph17155575

Zhu, N., Zhang, D., Wang, W., Li, X., Yang, B., Song, J., Zhao, X., Huang, B., Shi, W., Lu, R., Niu, P., Zhan, F., Ma, X., Wang, D., Xu, W., Wu, G., Gao, G. F., \& Tan, W. (2020). A novel coronavirus from patients with pneumonia in China, 2019. New England Journal of Medicine, 382, 727-733. https://doi. org/10.1056/NEJMoa2001017 